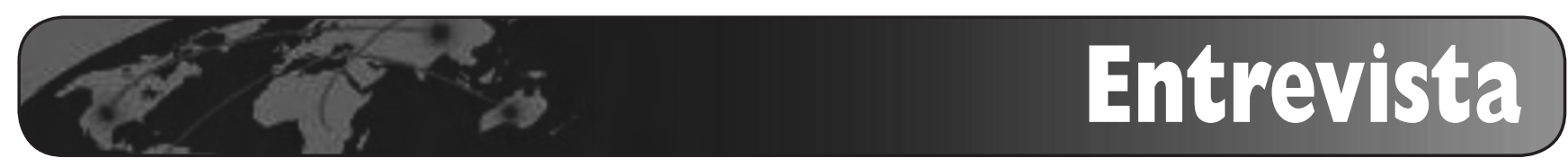

\title{
Reflexiones sobre bibliotecas. Entrevista a Lluís Anglada
}

\author{
Por Javier Guallar
}

\begin{abstract}
Resumen: Entrevista a Lluís Anglada, director del Consorci de Biblioteques Universitàries de Catalunya (CBUC). Entre otros temas, se trata la situación actual y el futuro de las bibliotecas, el papel de los consorcios de bibliotecas, la evolución del CBUC y de OCLC, y las políticas de acceso abierto.

Palabras clave: Biblioteca, Bibliotecas, Consorcios de bibliotecas, Cooperación bibliotecaria, CBUC, OCLC, Acceso abierto.

Title: Reflections on Iibraries. Interview with Lluís Anglada

Abstract: Interview with Lluis Anglada, director of the

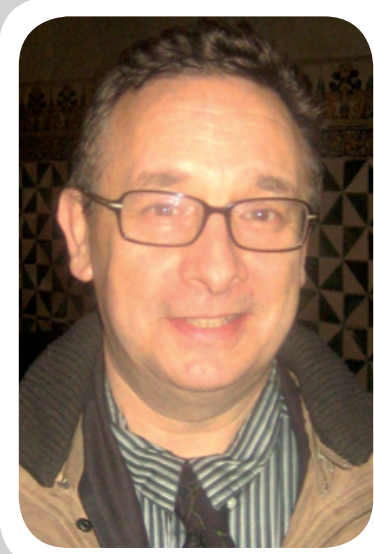
Lluís Anglada es director del Consorci de biblioteques universitàries de Catalunya (CBUC) desde 1997. Anteriormente fue director de las bibliotecas de la Universitat Politècnica de Catalunya y profesor de la Escola Universitària Jordi Rubió i Balaguer de Biblioteconomia i Documentació de Barcelona. Es licenciado en filosofía y diplomado en biblioteconomía. Desde 2009 es miembro de OCLC Global Council. Es autor y promotor de los blogs Bdig y Blok de Bid. Imparte regularmente talleres y conferencias y publica artículos sobre bibliotecas y consorcios bibliotecarios. Consortium of University Libraries of Catalonia (CBUC). Among other topics, the current and the future situation of libraries, the role of library consortia, the evolution of CBUC and OCLC, and the open access policies are discussed.
\end{abstract}

Keywords: Library, Libraries, Library consortia, Library cooperation, CBUC, OCLC, Open access.

Guallar, Javier. "Reflexiones sobre bibliotecas. Entrevista a Lluís Anglada”. El profesional de la información, 2010 , septiembre-octubre, v. 19, n. 5, pp. 545-551.

DOI: $10.3145 /$ epi.2010.sep.16

EN UN ARTÍCULO RECIENTE EN THINKEPI has definido la situación actual de las bibliotecas como "de una mala salud de hierro”. ¿Cómo ves el presente de las bibliotecas (tomando como referencia el caso de España)? ¿Cómo estamos?

- En un mundo en cambio acelerado como el actual, todas las instituciones viven una crisis constante de identidad. La que afecta a las bibliotecas tiene al menos 25 años de antigüedad y está asociada a las mejoras en acceso a la información que nos han traído los avances tecnológicos. La biblioteca "moderna" se presentó a sí misma como la institución que proporcionaba y facilitaba a la sociedad el acceso a los documentos. A medida que este acceso se ha liberado de la biblioteca edificio y del bibliotecario mediador en el imaginario popular, se ha empezado a dibujar la idea de un posible acceso del usuario a la información sin la mediación de la biblioteca. Pero las bibliotecas se han recreado a sí mismas: han reorganizado los espacios físicos para dar cabida a un uso de la información más social y menos individual, proporcionan alfabetización informacional a los usuarios, constituyen bibliotecas digitales, se preocupan de la preservación de los documentos electrónicos.

Hablando de España, las bibliotecas hoy con respecto a como las dejó el franquismo (y como las encontró mi generación) están bien, aunque en comparación con lo que deberían o podrían ser, son mejorables. Seguramente la repuesta debería hacerse por sectores y con más conocimiento de causa del que tengo.

Las bibliotecas universitarias han experimentado avances muy notables desde los años 90 y son se- guramente la punta de lanza de los servicios bibliotecarios en España. Creo que también sacan nota alta algunas fórmulas de cooperación y la formación universitaria en biblioteconomía y documentación. Las bibliotecas públicas han dado sin duda alguna un importante salto adelante, pero cuantitativamente presentan déficits notables y sin lugar a dudas podemos afirmar que hemos aprovechado poco los años de bonanza económica para satisfacer una serie de necesidades que ahora nos costará mucho llevar a cabo. Las bibliotecas nacionales han encontrado en la digitalización una actividad que les ha devuelto un protagonismo que en algún momento perdieron.

¿Los puntos débiles? A mi entender son dos: las bibliotecas escolares y el asociacionismo profesional. Las escolares porque el sistema 
educativo, ni en el ámbito estatal ni autonómico, ha sabido o podido crear al lado de las aulas aquellos centros de recursos o bibliotecas escolares que sirvieran de apoyo al proceso reglado de aprendizaje y que fueran los instrumentos para el proceso de autoaprendizaje. El asociacionismo profesional porque, después del acierto de federar las distintas asociaciones autonómicas, se ha refugiado en la formación profesional y ha abandonado el campo del lobismo y de la defensa de la profesión.

\section{"Puntos débiles: las bibliotecas escolares y el asociacionismo profesional"}

En este número de EPI dedicado a la "cooperación de bibliotecas en red" no podemos dejar de preguntarte por el Consorci de Biblioteques Universitàries de Catalunya, el CBUC. Como impulsor y principal cabeza visible, ¿nos puedes hacer una valoración de estos 14 años de historia, cómo se gestó, cuál ha sido su evolución y cómo encara el futuro?

- El origen del CBUC está en la voluntad de crear un catálogo colectivo por parte de las instituciones que en 1991 compartían un mismo software. Se quería mejorar la productividad de las bibliotecas al incrementar el porcentaje de catalogación por copia. De todas formas, el auténtico antecedente del Consorci debe buscarse en las diferentes experiencias de trabajo cooperativo que se llevaron a cabo entre las bibliotecas catalanas en la década de los ochenta.

La cooperación es buena para algunas cosas y mala para otras, pero, en todo caso, es una activi-

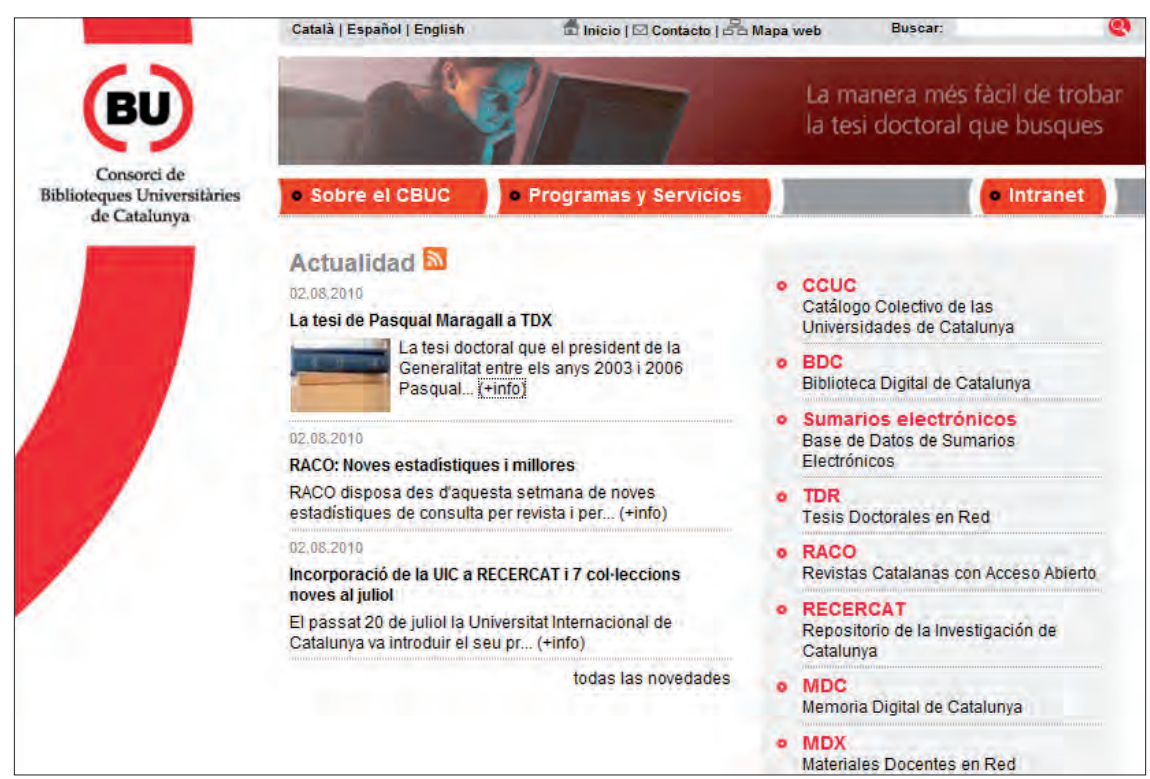

CBUC, http://www.cbuc.cat

dad que necesita ejercitarse para ser llevada a cabo. Uno de los tópicos más repetidos y menos realizados es que debemos cooperar más, pero del dicho al hecho hay un gran trecho. La reacción más natural de un individuo frente a un estímulo o problema es resolverlo solo, con sus propios medios. Descubrir que la solución puede encontrarse en la colaboración de varios individuos requiere un salto evolutivo. Cooperar es un acto complejo que requiere sustentarse en cuerpos sociales u organizacionales de cierta envergadura y madurez.

$\mathrm{Si}$ queremos hacer algo rápido, hagámoslo solos; si queremos hacer algo que tenga continuidad e influencia, hagámoslo colectivamente. Pero, insisto, la complejidad aparejada a la cooperación requiere un contexto que la favorezca y cierta práctica, cosas que se dieron a principios de los noventa, cuando decidimos formar el $C B U C$.

El Consorci logró en el breve plazo de dos años el objetivo para el que había sido concebido (la creación y mantenimiento del catálogo colectivo CCUC, Catàleg col-lectiu de les universitats de Catalunya). Esto ya lo justificaba, pero además ha sabido evolucionar ensanchándose en dos direcciones. Una es la de actividades: del Ccuc surgió el programa de préstamo interbibliotecario, el almacén para documentos de bajo uso, y los programas de contratación consorciada de recursos digitales y de depósitos cooperativos. La segunda dirección es la de miembros, ya que a los fundadores se han añadido como miembros asociados universidades privadas de Catalunya o públicas no catalanas que participan en la mayoría de programas. Además el $C B U C$ tiene un importante número de instituciones colaboradoras (por ejemplo, 84 entidades no miembros del Consorci colaboran con éste en el portal de revistas digitales Raco, Revistes catalanes amb accés obert).

\section{"Si queremos algo rápido, hagámoslo solos; si queremos que tenga continuidad $e$ influencia, hagámoslo colectivamente"}

A diferencia de las organizaciones individuales, las entidades cooperativas no se justifican por sí mismas, sino por el valor que aportan a sus miembros. En este sentido la pregunta a hacerse es ¿las biblio- 
tecas miembros del $C B U C$ estarían mejor o peor sin la existencia del mismo? La respuesta yo creo que es clara: están mejor con él. Son más competitivas porque tienen servicios que no tendrían sin la actividad cooperativa y porque algunos de sus costes son sensiblemente menores.

Los consorcios han crecido gracias a la información electrónica y a que ésta ha podido ser comprada de forma conjunta, pero de las compras conjuntas se ha dicho, por ejemplo, que sirven para comprar información que no se usa. ¿Qué opinas de ello? ¿Qué futuro tienen a escala internacional los consorcios basados en las compras de información digital?

- La información digital en la Red representa un cambio de entorno radical para el acceso y uso de la información. Una mirada superficial (que, por inmadurez, es la más frecuente) nos haría fijar en los efectos más superficiales del gran cambio: si leemos o no en html o pdf o sobre pantalla o teléfono móvil. A mi entender los cambios profundos derivados de este nuevo paisaje son sociales y organizativos. Sociales porque están generando nuevas pautas de uso de la información y organizativos porque el suministro de información se está dando en ambiente que tiene un nivel de complejidad más alto (y que, en este sentido, es superior) al que estábamos acostumbrados.

Retrocedamos 15 años en el tiempo. Las bibliotecas más ricas en colecciones de entonces son en muchos aspectos pobres en información en comparación con la que pueden suministrar hoy. $\mathrm{Y}$ esto es debido en gran parte a las compras consorciadas. El concepto de biblioteca de calidad se basaba en una debilidad que habíamos convertido en virtud: ya que no se podía tener todo de todo, tengamos lo mejor de una especialidad. Estuvo bien mientras funcionó, pero ahora podemos tener más. La biblioteca digital del
Consorci da acceso a unas 10.000 revistas electrónicas, lo que supone un $80 \%$ de los artículos científicos citados en la Web of Science.

No he oído a ningún usuario de biblioteca quejarse de tener demasiada información y sí a muchos que comentan que este incremento ha supuesto una mejora sustancial de su vida académica. A veces algunos bibliotecarios añoran el mundo en el que nacimos y crecimos, un mundo que comparado con el actual era de escasez, en el que el mediador (el bibliotecario) era "importante" porque regulaba el acceso al bien escaso que era la información.

Las cosas han cambiado y nosotros debemos cambiar con ellas: tener mucha información (parte de la cual puede no usarse) es bueno, en especial si sólo tiene un coste marginal. Por otra parte, en el reino de lo impreso y pre-consorcial, los documentos no usados de una biblioteca eran muchos: un $40 \%$ en bibliotecas con un presupuesto elevado para las adquisiciones. Diversos estudios han mostrado que el fenómeno de la larga cola (que no deja de cumplir la Ley de Bradford) se manifiesta en los paquetes de revistas y que son pocos los títulos que no son usados nunca.

Los consorcios actuales han nacido y crecido al rebufo de una actividad que se considera impura en la biblioteconomía: comprar más y a mejor precio. Pero yo creo que esta es una aproximación cultista y falsa. Las bibliotecas son organizaciones y como tales están sometidas a las leyes materiales del mundo: proporcionar servicios a partir de recursos y hacerlo de forma eficiente. De momento esto debe ser válido ya que se han creado consorcios de compras cooperativas en casi todo el mundo y los hay más donde los servicios bibliotecarios son mejores.

El futuro, ¿a cuántos años vista? Creo que las compras consor- ciadas aumentarán en los próximos 10 años. De hecho, una de las debilidades de nuestro sistema (debilidad basada en el prejuicio de que la clasificación de bibliotecas por tipos crea ámbitos estancos de cooperación) es la baja participación de bibliotecas de centros de investigación, hospitales, agencias del gobierno o públicas en las contrataciones cooperativas. Creo además que los consorcios, que en muchos casos han sido una respuesta coyuntural para obtener beneficios a corto plazo, se consolidarán si sacan partido a lo que saben hacer: coordinar esfuerzos para obtener un bien nuevo o para reducir costes.

\section{"Los consorcios se consolidarán si sacan} partido a lo que saben hacer: coordinar esfuerzos para obtener un bien nuevo o para reducir costes"

En marzo pasado fuiste elegido miembro del Consejo global de OCLC. Sabemos de las gigantescas dimensiones de esta organización de 27.000 bibliotecas en 171 países, pero ¿qué influencia está teniendo sobre las bibliotecas españolas?

- OCLC fue un consorcio más de los muchos que se crearon en los Estados Unidos y en Europa en los años 70 alrededor de la automatización de los catálogos de las bibliotecas. La motivación era el ahorro de costes en catalogación y automatización y aquella aceleración de la cooperación propició que surgieran múltiples entidades cooperativas, algunas de las cuales continúan existiendo a pesar de que otras muchas han desaparecido.

No existen ya la ejemplar PICA de Holanda ni los consorcios regionales del Reino Unido, pero en los 
países nórdicos han perdurado estructuras cooperativas de catalogación y de catálogos colectivos sobre las cuales a veces se han sustentado los consorcios de compras digitales actuales. En los EUA, OCLC tomó preeminencia en el proceso cooperativo de catalogar por copia. Esto sustentó a OCLC económicamente y permitió a las bibliotecas norteamericanas completar sus procesos de reconversión de catálogos con plazos y costes mejores que lo que han podido hacer las de otros países.

Lo mejor del crecimiento de $O C L C$ por encima de otros consorcios o redes de bibliotecas, es que no ha sido a costa de la desaparición de los que quedaban atrás en dimensiones o de la no creación de nuevas entidades organizativas. Quien observe la realidad asociativa y consorcial norteamericana descubrirá una enorme cantidad y variedad de instituciones cooperativas que coexisten con $O C L C$ y que lo hacen a veces con servicios paralelos de catálogo colectivo y préstamo interbibliotecario.

Su preeminencia en el suministro de catalogación por copia la ha convertido en un monopolio de facto y así ha sido percibida en algunas partes del mundo y, concretamente, en la Europa no anglosajona, España incluida. En los EUA ha habido un fuerte debate debido a cambios sobre las condiciones de uso de los registros de WorldCat. Yo mismo en el pasado me he sentido maltratado por una organización que se reclamaba hija de las bibliotecas y actuaba con la insensibilidad y rigidez que atribuimos a las empresas multinacionales.

Pero es una organización de grandes aciertos. Presta servicios a las bibliotecas con la copia de registros, tienen un préstamo interbibliotecario a escala internacional y la red virtual de referencia bibliográfica Question Point, distribuye software específico para bibliotecas

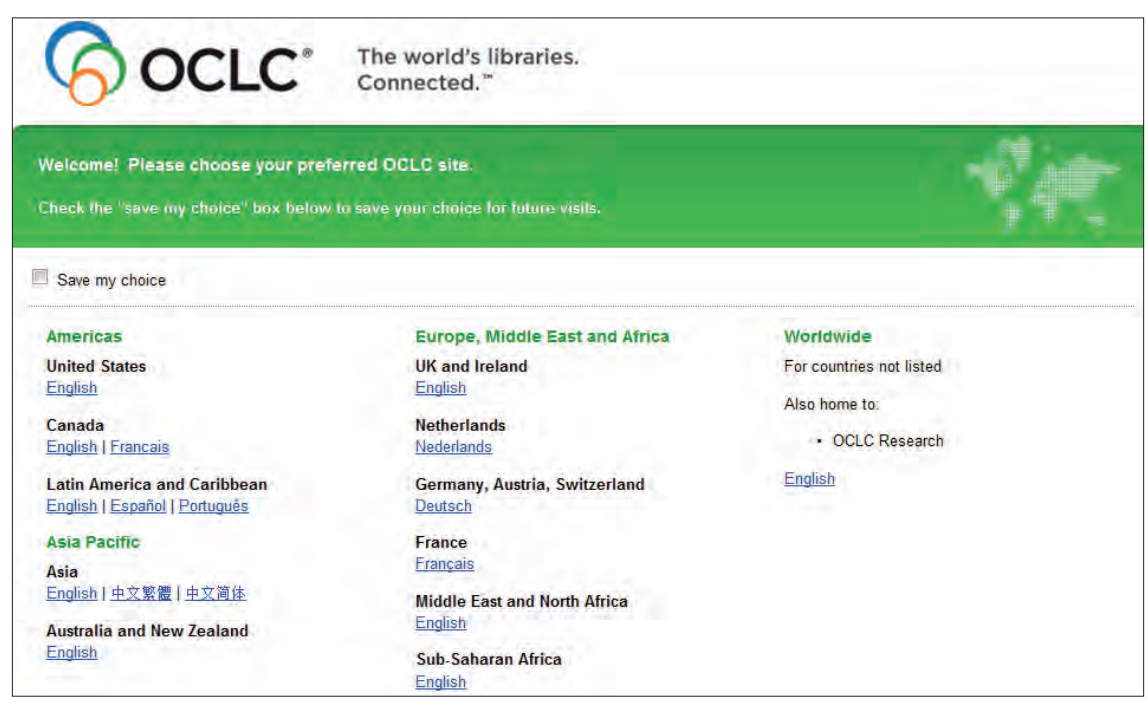

OCLC, http://www.oclc.org

como Content.dm, mantiene $\mathrm{Du}$ blin Core... Pero su función más importante es la de hacer de escaparate para las bibliotecas a escala mundial. WorldCat, que tenía unos "escasos" 40 millones de registros bibliográficos hace unos pocos años, reseña hoy casi 200 millones con noticias bibliográficas de todo tipo de documentos y procedentes de bibliotecas, archivos y museos. WorldCat exhibe al mundo los contenidos de las instituciones de la memoria y hace que, sin esfuerzo por parte de éstas, sus documentos aparezcan en la Red cuando se hacen búsquedas globales.

Recientemente ha tomado la decisión de internacionalizarse, esto quiere decir que ha abierto de forma decidida su gobierno a bibliotecas no estadounidenses y que quiere reorganizarse para ser una organización global. A mi entender las bibliotecas necesitamos organizaciones internacionales fuertes. Necesitamos asociaciones profesionales, entidades cooperativas y empresas suministradoras de servicios a escala global porque muchas de las batallas del futuro se librarán en la arena de lo global. Otras batallas serán en el terreno de lo local, y por esto hemos de aprovechar las oportunidades que puedan presentarse para influir desde nuestro punto de vista y situación en orga- nizaciones internacionales. Cuando me presenté como candidato para el Consejo global de OCLC fue con esta intención.

\section{"La función más importante de OCLC es la de hacer de escaparate para las bibliotecas a escala mundial"}

Eres también un actor en la primera línea de las políticas de Open access y has sido el promotor del OA Seminar en Granada, que tuvo como primer resultado la Declaración de la Alhambra del 14 de mayo de 2010 sobre promoción del acceso abierto en los países del sur de Europa. ¿Cuál es la situación del OA en estos momentos y cómo ves su proyección?

- A mí como bibliotecario lo que me interesa es mejorar el acceso a la información. Esto puede y debe realizarse de diferentes formas: coleccionando material efímero y de escaso valor presente, organizando sesiones de formación en el uso de bases de datos o mejorando la distribución física del espacio de la biblioteca. Se hace comprando o subscribiendo información, acti- 
vidad loable que, por haber dinero de por medio, sufre cierto desprestigio entre una profesión muy volcada a actividades altruistas. Ahora tenemos la oportunidad de mejorar el acceso a la información contribuyendo a la consolidación y expansión del movimiento del acceso abierto.

Los bibliotecarios estamos dentro del circuito de creación y consumo de información y, concretamente, de la información científica. En esta cadena ocupamos lugares a veces de protagonismo (en la difusión de la información), a veces de auxiliares. La cadena de difusión de información científica está en proceso de cambio. Ha sido más o menos estable en los casi cuatro siglos que nos preceden, pero la digitalización de la información y su distribución por la Red han introducido variaciones notables cuyo resultado final es todavía incierto. La citada compra de información por paquetes y de forma consorciada es una de las principales. Poner información en la Red de forma libre, y el acceso abierto a información que otros han puesto es otra de las componentes de este cambio que está de momento insinuando alternativas. Nuestra tarea como profesionales es favorecer las formas de distribución de información que redunden en mejoras para los usuarios.

La implicación de las bibliotecas en el OA es alta y esto está bien porque el movimiento está teniendo diversas consecuencias beneficiosas: incrementa la cantidad de información disponible, reduce el poder del oligopolio de las editoriales y sociedades que publican la principal información científica, y expone la información para que pueda ser usada en contextos distintos al que nacieron. Está bien además porque ha dado a las bibliotecas más juego. Hemos entrado en la cancha para sostener un movimiento que de momento tiene más influencia que poder. Y digo esto porque al mismo

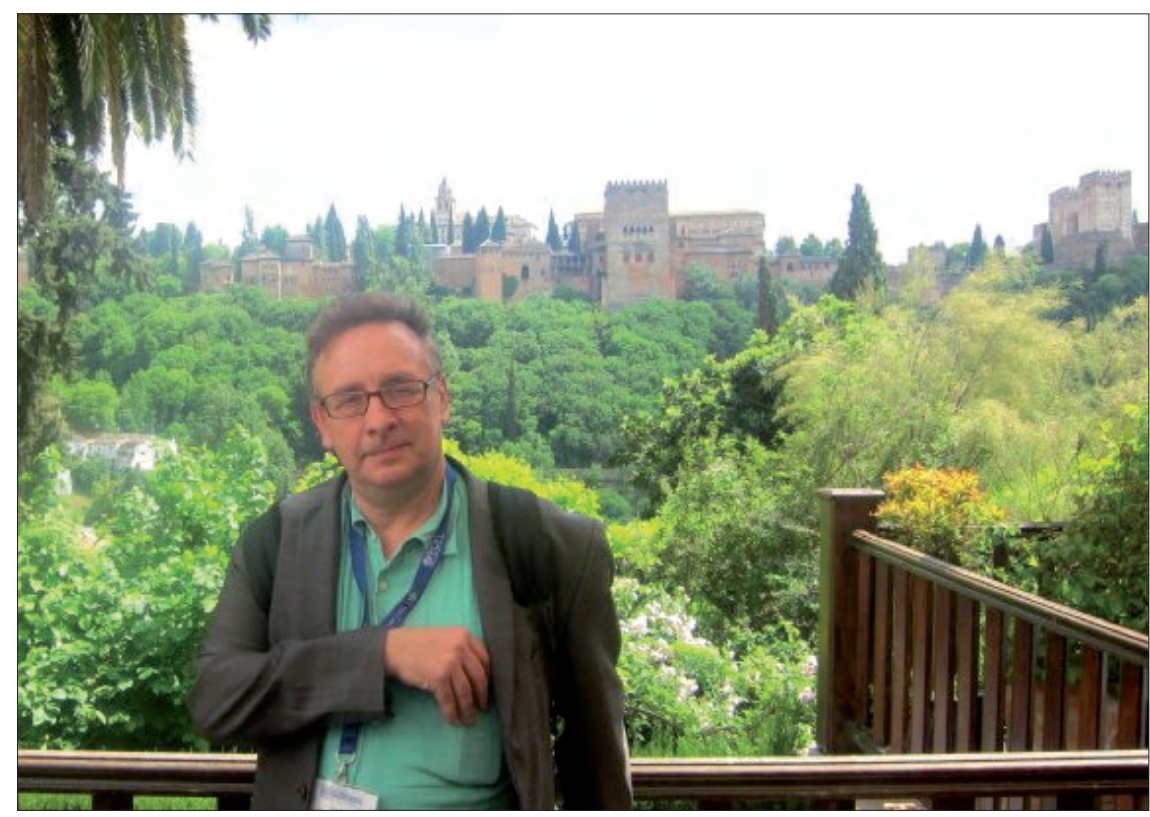

Lluís Anglada durante el OA Seminar de Granada, mayo 2010

tiempo que la información disponible en OA es aún minoritaria, la existencia de repositorios de información es uno de los elementos que hoy está influyendo fuertemente en la elaboración de actividades al servicio de la ciencia.

Hace diez años, consorcios de Turquía, Grecia, Italia, España y Portugal (a los que se ha sumado recientemente Francia) nos reunimos para aprender los unos de los otros y mejorar nuestras posiciones con respecto a lo que hacemos. Hace un par de años quisimos incluir el OA en nuestras agendas ya que muchas de nuestras actividades tenían que ver con los repositorios. Nos propusimos redactar informes nacionales pera ver el estado del OA en los respectivos países, poder comparar situaciones y sacar aprendizajes. Le propusimos a la Fecyt que acogiera un encuentro sobre el OA en los países de los consorcios mencionados.

La idea era simple: reunir delegaciones nacionales formadas por personas representativas de los diferentes agentes que intervienen en la cadena de la comunicación académica para discutir los informes nacionales mencionados (y una copia de lo que habían hecho hace un par de años los países nórdicos) e identificar posibles medidas de soporte del OA. Se busca que las medidas aprobadas por expertos de diferentes países sirvan de apoyo a los esfuerzos que cada uno realiza por su lado. La reunión tuvo lugar en Granada el pasado mes de mayo y concluyó con una declaración que señala en qué ámbitos debemos avanzar y cómo hacerlo para dar apoyo al acceso abierto.

\section{http://oaseminar.fecyt.es/Publico/ AlhambraDeclaration/index.aspx}

Quizá lo más importante de la Declaración OA de Granada sea el compromiso de las instituciones y personas asistentes de constituir en cada país una "taskforce" representativa en la que participen personas de los diferentes agentes implicados en la cadena de producción científica y el de realizar anualmente un plan de acción nacional para la promoción y extensión del movimiento.

Otra faceta tuya muy interesante es tu actividad en la Red, en dos blogs tan atractivos como Bdig y Blok de BiD, uno es un blog personal y en el otro coordinas a varios autores. Háblanos de ambos.

- Desde mi punto de vista, lo que uno es como profesional queda conformado por lo que ha aprendi- 
do, por lo que ve y por lo que lee. La formación recibida, recibida está y la realidad que nos rodea es difícil de cambiar, pero está en nuestras manos informarnos profesionalmente para ser mejores profesionales. Tenemos la inmensa suerte de ser una profesión que cree en la información y que pone por escrito las más variadas experiencias. No todas son extrapolables a nuestra realidad, pero muchas sí, y casi todas nos enriquecen como profesionales.

\section{"Lo que uno es como profesional queda conformado por lo que ha aprendido, lo que ve y lo que lee"}

Empecé el blog Bdig con la intención de llamar la atención sobre la aparición y existencia de informes profesionales que podían tener interés para bibliotecarios que batallan en diferentes frentes. Mi intención era fomentar su lectura (y no ahorrarla) suministrando los contenidos principales de los informes. Pero un blog es un instrumento personal con el que uno hace lo que quiere y aquella intención inicial quizá fue quedando un tanto desplazada por las experiencias personales que terminan imponiendo un rumbo errático (y perdón por la contradicción en los términos).

\section{http://bdig.blogspot.com}

La idea original era buena, pero su realización requería un marco más amplio, un entorno que permitiera la integración fácil de más personas en el proyecto y más soporte técnico y de redacción. La Facultat de Biblioteconomia i Documentació de la Universitat de Barcelona se ha prestado gustosamente a ello y hemos encontrado una simbiosis con la revista $B i D$, que en sus po-

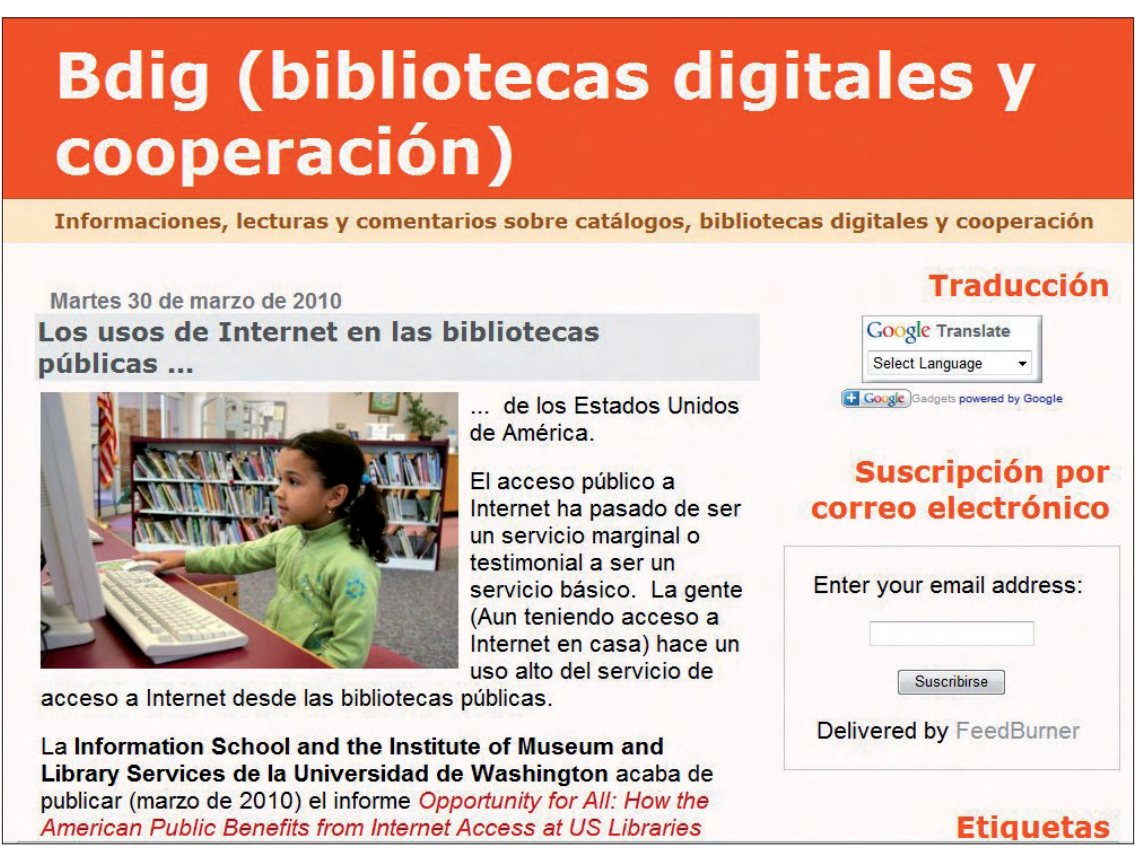

Bdig, http://bdig.blogspot.com

cos años de existencia se ha hecho un lugar en el campo profesional hispano. BiD nació en el entorno digital pero tiene una estructura tradicional de revista. Con Cristóbal Urbano, el decano de la Facultad, consideramos que $B i D$ podía enriquecerse con un blog que reseñara información profesional y que la voluntad de informar a la comunidad profesional sobre informes técnicos, productos o congresos puede aprovecharse del nombre y trayectoria de la revista.

El Blok de BiD quiere ser lo que se ha expresado: un instrumento para estar al día profesionalmente hablando, sea porque se dirige la atención a la lectura misma de los textos originales, sea por la información sobre los mismos suministrada en los propios resúmenes. Ahora mismo los coordinadores somos Ernest Abadal, Candela Ollé y yo mismo y estamos manejando un pequeño grupo de unos 10-12 reseñadores. Queremos llegar a finales de año contando con un equipo de colaboradores algo mayor, sin que lo sea mucho más. Queremos que especialistas en un tema proporcionen resúmenes con autoridad, útiles, de informes publicados en internet. Intentamos ser un poco más informativos y valorativos que $\mathrm{Cu}$ rrent Cites, por ejemplo, sin llegar a publicar los estados de la cuestión que aparecen en ThinkEPI.

http://www.ub.edu/blokdebid/es

Hemos empezado hablando del presente de las bibliotecas y vamos a terminar haciéndolo del futuro. Lee Rainie decía en la conferencia inaugural de las recientes Jornades Catalanes de Documentació que las bibliotecas en el nuevo ecosistema digital deberían jugar un papel como nodos de las redes sociales que establecerán cada vez más las personas. ¿Qué opinas de este argumento y cómo ves el futuro de las bibliotecas en este futuro digital, en el cual, como has dicho en tu blog, quizá ya no sean tan “indispensables"?

- Como institución, la biblioteca es muy antigua. Hay pocas organizaciones que hayan resistido el paso del tiempo tan bien como lo han hecho las bibliotecas. Cierto es que las bibliotecas de hoy se diferencian bastante de las que hubo en Roma o en la Edad Media, pero la "biblioteca" permanece. Esto ha sido así porque las bibliotecas han sabido recrearse o reinventarse cuando la situación lo ha exigido. 
Las bibliotecas pusieron los libros bajo cadenas cuando éstos eran bienes escasos, los recogieron cuando la desamortización de bienes eclesiásticos los dispersaba, los coleccionaron cuando fue necesario organizar el saber y los difundieron cuando la sociedad necesitó apoyo para la extensión de la alfabetización.

\section{"El futuro de bibliotecas depende de dos factores: la evolución de las necesidades sociales con respecto a la información y la capacidad de las bibliotecas de satisfacerlas"}

La existencia futura de bibliotecas depende de dos factores: de la evolución de las necesidades sociales con respecto a la información y de la capacidad de las bibliotecas de satisfacerlas. Las bibliotecas no son indispensables hoy y quizá no lo hayan sido nunca. Por desgracia, nuestras sociedades han dado sobradas muestras de cómo son prescindibles la paz, la justicia social, la cultura. ¿Por qué las bibliotecas serían una excepción a esto?
Si una institución es útil a la sociedad, permanece. Algunas instituciones sin utilidad pueden prolongar su vida de forma forzada, pero terminan por perecer. La clave no es ser indispensable (algo que es sólo alcanzable por don divino), sino ser necesario (algo al alcance de la mano del esfuerzo humano). La pregunta no es si la humanidad puede vivir sin bibliotecas, sino qué podemos hacer las bibliotecas para hacer más fácil y agradable la existencia humana. En la sociedad de la información debería ser fácil que los que hemos tenido la información como profesión pudiéramos aportar algo a la sociedad.

El malentendido se debe seguramente a que el concepto actual de biblioteca para el sentir popular se basa en lo que las bibliotecas aportaron como valor en una época en la que la información era un bien escaso: colecciones de saberes. Hoy la información es un bien de un acceso bastante fácil y el valor ya no está en la acumulación de información sino en la capacitación sobre su uso y en la facilitación de la transformación de la información en conocimiento.

¿La biblioteca debe o puede ser un nodo de las redes sociales? Quizá sí, pero no sólo esto. El acceso libre a la información mundialmente disponible será aún durante algún tiempo un desideratum, como lo son los derechos humanos a muchos años de su universal promulgación. La conservación del saber no está garantizada por una sociedad utilitarista, la formación crítica en el uso de la información no se circunscribe al ámbito escolar, la oferta variada de información de calidad no puede dejarse en manos de lo que se encuentre en la Red... Es decir, aún hay campo para recorrer en lo podríamos definir como los ámbitos tradicionales de la biblioteca. Más allá de éstos, las bibliotecas pueden ser nodos de las redes sociales, agentes facilitadores de la generación de conocimiento o terceros espacios o espacios sociales donde ejercer de ciudadano en la sociedad de la información.

Tenemos futuro si tenemos la inteligencia de saber leer las necesidades sociales y la flexibilidad de adaptarnos a ellas para satisfacerlas.

\section{Lluís M. Anglada i de Ferrer \\ Consorci de Biblioteques Universi- tàries de Catalunya (CBUC) \\ Gran Capità, 2-4. Edif. Nexus, 3a planta. 08034 Barcelona \\ langlada@cbuc.cat}

Javier Guallar. Universitat de Barcelona, Facultat de Biblioteconomia i Documentació. jguallar@gmail.com 


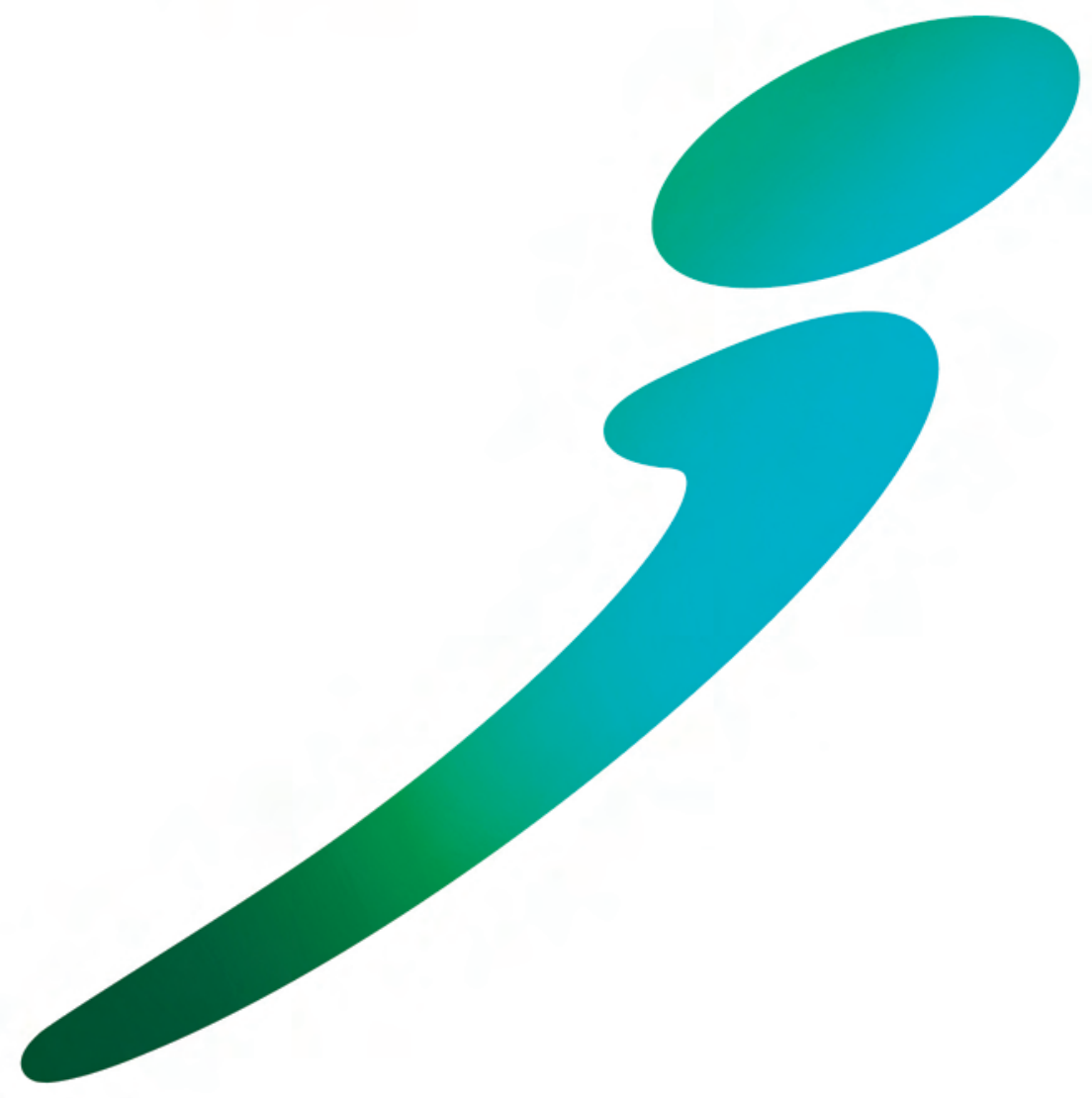

\section{Discover new ways of working in the linked and social web}

ONLINE

INFORMATION CONFERENCE 2010

Opening Keynote speaker: Dion Hinchcliffe Well known Fortune 100 Business Strategist and Enterprise Architect; Author of numerous books \& articles on Web 2.0; Top Social Media \& Collaboration Expert

Hear from: Åbo Akademi University, Amazon, Dutch Parliament, Guardian News \& Media, Mid-Sweden University, National Archives, PwC Canada, Royal Society of Chemistry, Shell and many more!

Learn from more than 90 information industry experts and join your peers from over 40 countries to hear about:

- Leadership skills for collaboration and proving value using social media

- Linked and open data projects in government, business and libraries

- Information Professionals demonstrating value and impact

- How mobile devices and 'the cloud' are being used to deliver information services

Automatic free entry to the Online Information Exhibition which runs alongside the conference.

View full programme information and book your place at www.online-information.co.uk/conference

SUPPORTED BY
a ip
1.A Archives \& Records
ESIn:
ANIPSP
A bima
cilip
clsia

间

dfid

*: * eija

Freepint
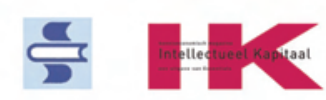

* The Information Architecture Institute 